\title{
Effects of Ghrelin on the Intracellular Calcium Concentration in Rat Aorta Vascular Smooth Muscle Cells
}

\author{
Huan Fang ${ }^{a}$ Zhen Hong ${ }^{b} \quad$ Jun Zhang ${ }^{a}$ Dai-Fei Shen ${ }^{c} \quad$ Fen-Fei Gao ${ }^{c}$ Kenji Sugiyama \\ Hiroki Namba ${ }^{d}$ Tetsuya Asakawad \\ aDepartment of Pharmacy, Jinshan Hospital of Fudan University, Shanghai, P.R of China; \\ bDepartment of Neurology, Huashan Hospital of Fudan University, Shanghai, P.R of China; \\ 'Department of Pharmacology, Shantou University Medical College, Shantou, P.R of China; \\ dDepartment of Neurosurgery, Hamamatsu University School of Medicine, Hamamatsu-city, \\ Shizuoka, Japan
}

\section{Key Words}

Ghrelin • Vascular smooth muscle cells • Intracellular calcium • AngII • Sq22536

\begin{abstract}
Background/Aims: Ghrelin has been regarded as a cardioprotective factor with complicated mechanisms. Whether ghrelin is vasodilative or vasoconstrictive in nature is controversial, and the effects of ghrelin on intracellular calcium concentration are still unclear. To explore the mechanisms involved in the vasoactive regulation of ghrelin at the cellular level, we investigated the effects of ghrelin on calcium concentrations in rat aorta vascular smooth muscle cells (VSMCs). Methods: We obtained VSMCs via cell culture and stained the cells with Furo-2 AM. Western blotting was used to verify growth hormone secretagogue receptor (GHSR1a) expression in VSMCs. The intracellular calcium variations affected by ghrelin and the interactions of ghrelin with angiotensin II (AngII), Sq22536, and potassium chloride (KCl) were observed using a calcium imaging and analysis system. Results: Western blotting revealed good GHS-R1a expression in VSMCs. The most prominent finding in the present study was that ghrelin inhibited the AngII-induced increase in the calcium concentration. This inhibition was reversed by the adenylate cyclase inhibitor Sq22536 and the GHS-R1a antagonist (D-Lys s)GHRP-6. This finding revealed the potential vasodilative effects of ghrelin at the cellular level. We did not observe any effects of ghrelin on intracellular calcium concentrations in resting VSMCs or the increase of calcium concentration induced by KCl. Conclusion: Ghrelin inhibited the increase in the intracellular calcium concentration of rat aorta VSMCs induced by AngII, which may depend on the activation of the CAMP/PKA pathway.

Copyright @ 2012 S. Karger AG, Basel

Tetsuya Asakawa, M.D., Ph.D.

or Fen-Fei Gao, Ph.D.

Department of Neurosurgery, Hamamatsu University School of Medicine Handayama, 1-20-1, Higashi-ku, Hamamatsu-city, Shizuoka, 431-3192, (Japan)

or Department of Pharmacology, Shantou University Medical College

No. 22 Xinling Road, Shantou 515041 (China)

E-Mail fangxin@hama-med.ac.jp, or E-Mail ffgao@stu.edu.cn
\end{abstract}




\section{Introduction}

Ghrelin, an acylated 28-amino acid gut-brain peptide, is predominantly produced by the stomach oxyntic mucosa. It is the endogenous ligand of the hormone secretagogue receptor (GHS-R) [1]. GHS-R is widely expressed in the central and peripheral tissues, but circulating ghrelin is mainly expressed in the gastric mucosal X/A-like cells ( $>90 \%$ of the body's ghrelin stores) [2-4]. In addition to the gastrointestinal tract, some expression was also identified in the endocrine organs (ovary, anterior pituitary, and adrenal gland) [5], pancreatic islets [6], hypothalamus [7], and cardiomyocytes [8]. In the cardiovascular system, ghrelin and GHS-R are distributed in the arteries, heart, veins, and vascular endothelial cells, and they affect the regulatory functions of the heart and vasculature [9-12]. Two main molecular forms of ghrelin are reported, namely acylated ghrelin and desacyl ghrelin. In acylated ghrelin, serine in position 3 is n-octanoylated by ghrelin- $O$-acyltransferase, and this n-octanoylation is crucial for ghrelin binding to its receptor (GHS-R1a) and exerting its biologic activity [1314]. Both forms of ghrelin are predominantly derived from gastric X/A-like cells. The amount of desacyl ghrelin far exceeds that of acylated ghrelin, and the ratio of desacyl ghrelin and acylated ghrelin in the blood was reported to fluctuate from 15:1 to 55:1 [13-15]. The exact receptor for desacyl ghrelin is unclear. Most previous studies focused on the acylated form, usually referred to as "ghrelin" in the literature [16], we used acylated ghrelin in the present study.

Ghrelin is a cardioprotective factor that reduces the circulatory levels of catecholamines, rennin, angiotensin II (AngII), aldosterone, and endothelin-1 (ET-1) in rats with heart failure in addition to significantly decreasing arterial pressure in humans and rats [12, 17-19]. The effects of ghrelin on vascular smooth muscles can be observed by assessing the artery rings using a myograph or vascular smooth muscle cells (VSMCs) by the patch clamp technique [20-22]. Nevertheless, whether ghrelin is vasodilative or vasoconstrictive in nature is contradictory among studies depending on the vessels examined [23-24]. It is hypothesized that ghrelin may play a role VSMC adjustment by affecting intracellular calcium concentrations.

The known intracellular mechanisms involved in ghrelin signaling pathways are complicated. Ghrelin has been reported to activate several intracellular signaling pathways. First, ghrelin primarily binds to GHS-R1a, which preferentially activates Gq-protein and phospholipase C (PLC) and mobilizes calcium release from inositol 1, 4, 5-triphosphate $\left(\mathrm{IP}_{3}\right)$ stores [25]. This a classic well-described pathway that is commonly used to explain the vasoconstrictive effect of ghrelin in rat coronaries, guinea pig femoral arteries, and other contexts [21,23]. In addition, ghrelin activates two other targets: (1) adenylate cyclase (AC) and cAMP-dependent protein kinase (PKA), namely the AC/cAMP/PKA signaling pathway in the endothelial and smooth muscle cells of the human aorta [11,22, 26] and bladder [27] and (2) pancreatic $\beta$-cells in rats [28]. It also modulates cGMP production and cGMP-dependent protein kinase (PKG) in the GH3 rat pituitary tumor cells [29]. Recent reports indicated that the extracellular signal-regulated kinases 1 and 2 were also enhanced by ghrelin in both mouse VSMCs [30] and human endothelial cells [26, 31].

However, the effects of ghrelin on the intracellular calcium concentrations of VSMCs are still unknown. To achieve a deeper understanding of the mechanisms involved in the vasoactive regulation of VSMCs, we investigated the effects of ghrelin on intracellular calcium concentrations in VSMCs using a calcium imaging and analysis system.

\section{Materials and Methods}

Animals and materials

Fifteen male Sprague-Dawley (SD) rats (200 $\pm 10 \mathrm{~g})$ were obtained from the Experiment Animal Center, Shantou University Medical College. The animals were cared for and treated as per the guidelines of the Guide for the Care and Use of Laboratory Animals published by the US National Institutes of Health (NIH 
Fang/Hong/Zhang et al.: Ghrelin, AngII and Intracellular Calcium

Publication No. 85-23, revised 1996). All experimental protocols were supervised by the Laboratory Animal Ethics Committee of Shantou University Medical College.

\section{VSMCs culture}

Rat aorta VSMCs were obtained and cultured as described previously [32]. In brief, rats were anesthetized with $10 \%$ chloral hydrate $(0.4 \mathrm{~mL} / 100$ g; i.p.). The thoracic aortae were removed from the fat and connective tissues and cleaned. The endothelium was removed, and the smooth muscle layer was cut into segments of $1 \mathrm{~mm}^{2}$. Next, the VSMC tissues were placed in M199 medium containing 20\% FBS (only for primary culture), penicillin $\left(1 \times 10^{5} \mathrm{U} / \mathrm{L}\right)$, and streptomycin $(100 \mathrm{mg} / \mathrm{L})$ and cultured with $5 \% \mathrm{CO}_{2}$ at $37^{\circ} \mathrm{C}$. Cells in the third to fifth generations (cultured with 10\% FBS) were placed in Petri dishes and incubated for $36 \mathrm{~h}$ continuously in preparation for staining.

Western blotting to verify GHS-R1a expression in VSMCS

Western blotting was performed as described previously [33-34]. In brief, VSMCs $\left(5 \times 10^{6}\right)$ were lysed in lysis buffer (10 mM Tris-buffered saline, $1 \mathrm{mM}$ EDTA, $2 \mathrm{mM}$ sodium orthovanadate, $0.2 \mathrm{mM}$ PMSF, $2 \mu \mathrm{g} /$ $\mathrm{mL}$ leupeptin, $2 \mu \mathrm{g} / \mathrm{mL}$ aprotinin, and 1\% Triton X100). Protein was loaded onto SDS-PAGE gradient gels, separated, and electrophoretically transferred onto polyvinylidene difluoride membranes. The blots were blocked by incubation in TBST [10 mM Tris-HCl (pH 7.5), $150 \mathrm{~g} \mathrm{NaCl}$, and $0.1 \%$ Tween 20] containing 5\% skimmed dried milk for $1 \mathrm{~h}$ at room temperature. After washing, the membranes were probed with the primary antibody (rabbit anti-rat GHS-R1a, Phoenix Pharmaceuticals). The signal was revealed using an enhanced chemiluminescence detection kit (Pierce) after reacting with the second antibody.

\section{Calcium fluorescence intensity (FI) measurement and analysis}

Fura-2 AM was dissolved with cosolvent Pluronic F-127 (1 mmol/L). VSMCs were washed twice with cell physiological solution $(134 \mathrm{mM} \mathrm{NaCl}, 6 \mathrm{mM} \mathrm{KCl}, 1 \mathrm{mM} \mathrm{MgCl}, 2 \mathrm{mM} \mathrm{CaCl}, 10 \mathrm{mM}$ glucose, and $10 \mathrm{mM}$ HEPES, pH 7.4) and incubated for 20 min with $200 \mu \mathrm{L}$ of cell physiological solution containing $5 \mu \mathrm{mol} / \mathrm{L}$ Fura-2 AM. The cells were then washed twice with cell physiological solution, and $2 \mathrm{~mL}$ of the same solution was added to the Petri dishes.

The calcium imaging and analysis system, which consists of an Axiovert 2000 fluorescence microscope (Carl Zeiss, Germany), CCD cameras (Hamamatsu ORCA-ER, Japan), and an Ultra High Speed Wavelength Switcher (LAMBDA DG-4, Sutter, USA), was used for observing intracellular calcium variations. After the staining sample was prepared, we selected a $\times 40$ oil object lens and switched the optical path to CCD when the cells were brought into focus. PCI 6.0 calcium imaging system software was used to capture and analyze the calcium images (the excitation wavelengths were 340 and $380 \mathrm{~nm}$ in the Fura-2 module). The parameters were optimized to maximize the image quality in prescanning accordingly. The relative calcium concentration was expressed as the FI ratio of FI at 340 and $380 \mathrm{~nm}$ as follows:

FI ratio $=\geq \mathrm{FI}_{(340)} / \geq \mathrm{FI}_{(380)}$,

Where $\geq F I$ is the average FI of the selected cytoplasm area minus the average background FI.

\section{Drug administration}

The stock solutions including $5 \times 10^{-4}$ and $5 \times 10^{-6} \mathrm{~mol} / \mathrm{L}$ acylated ghrelin (Sigma, USA), $4 \mathrm{~mol} / \mathrm{L} \mathrm{KCl}$, $2 \times 10^{-5} \mathrm{~mol} / \mathrm{L}$ AngII, and $1 \times 10^{-3} \mathrm{~mol} / \mathrm{L}$ Sq22536 were prepared, and $20 \mu \mathrm{L}$ of each solution (which were diluted 100 -fold) were added to $2 \mathrm{~mL}$ of cell physiological solution in the respective Petri dishes. To validate the specificity of the observed acylated ghrelin-induced inhibition of AngII-stimulated intracellular calcium elevation, we prepared $5 \times 10^{-4} \mathrm{~mol} / \mathrm{L}(1: 1$ with the concentration of ghrelin after being diluted, namely 5 $\times 10^{-6} \mathrm{~mol} / \mathrm{L}$ ) GHS-R1a antagonist (D-Lys ${ }^{3}$ )-GHRP-6 solutions (Mocell, Shanghai, P.R of China) according to previous studies [22,35], and $20 \mu \mathrm{L}$ of each solution was added to $2 \mathrm{~mL}$ of cell physiological solution (which were diluted 100-fold) in the sequence of acylated ghrelin, (D-Lys ${ }^{3}$ )-GHRP-6, and AngII.

\section{Data analysis and statistics}

All data were recorded as the mean \pm SD. The rate of change of the intracellular calcium concentration was obtained by calculating the FI ratio after stimulation to the resting state FI. Statistical analysis of drug effects was performed using a self-control paired t-test. $P<0.05$ was considered statistically significantly. 
Fig. 1. Western blotting of GHS-R1a expression in rat aorta VSMCs. Rabbit anti-rat GHS-R1a antibody bound a component of the membrane with a molecular weight of $41 \mathrm{kDa}$, and good GHS-R1a expression in rat aorta VSMCs was observed.

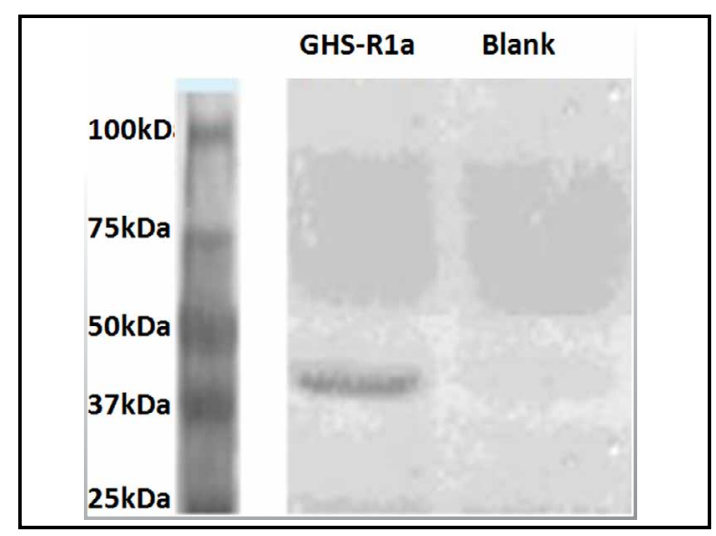

A B
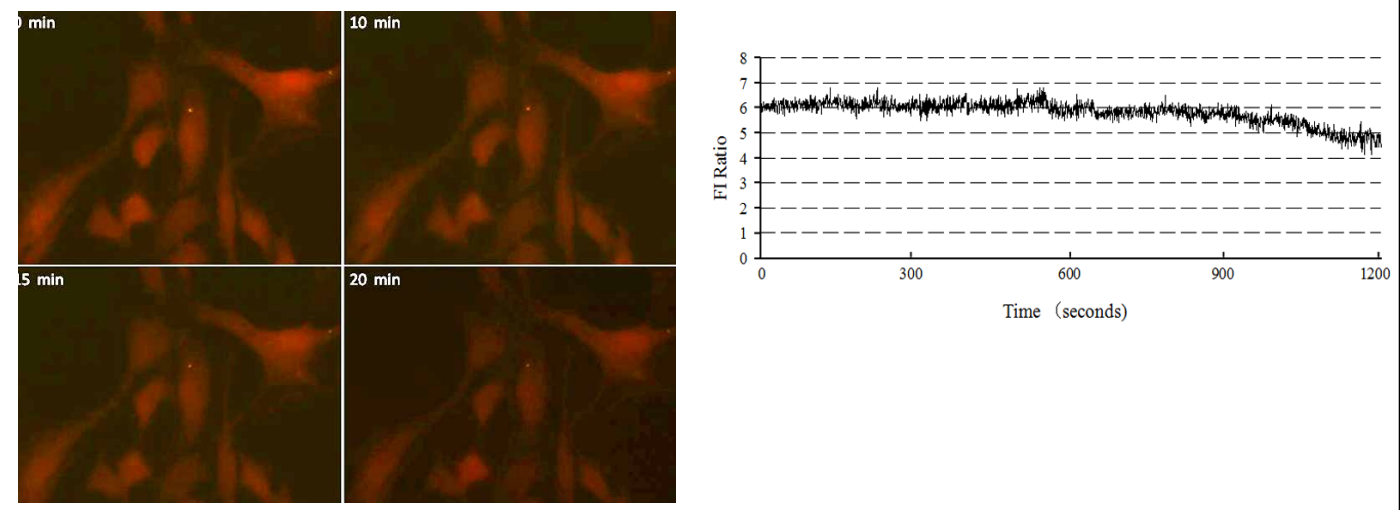

Fig. 2. Results of the FI stability examination. (A) Images of calcium FI taken using the calcium imaging and analysis system $(\times 400)$. The luminance of the fluorogram corresponds to calcium concentration; i.e., increased brightness of the fluorogram indicates a higher calcium FI ratio. (B) Time curve of the intracellular calcium FI ratio. Our data revealed that the FI ratio was stable for $15 \mathrm{~min}$ after initiation, after which it began to attenuate. The stability of the experimental system was confirmed.

Fig. 3. Influence of ghrelin on the intracellular calcium FI ratio in resting VSMCs. Administration of $5 \times 10^{-8}$ and $5 \times 10^{-6} \mathrm{~mol} / \mathrm{L}$ ghrelin did not affect the calcium FI ratio of resting VSMCs.

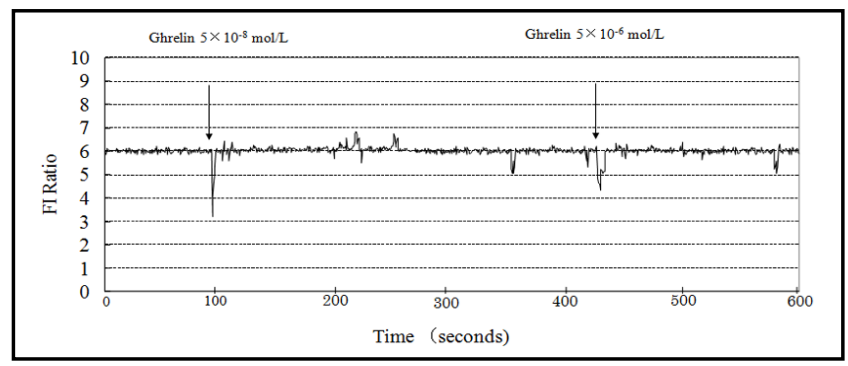

\section{Results}

Examination of GHS-R1a in VSMCS

Figure 1 shows antibody binding to an approximately 41-kDa component of the membrane, which corresponds to the molecular weight of GHS-R1a. It was confirmed that GHS-R1a was well expressed in rat aorta VSMCs. This result was consistent with that of a previous study [33].

\section{Examination of FI stability}

Figure 2 shows that the FI ratio remained unchanged in the first 15 min after which it was attenuated. Fluorescence quenching by excitation therefore can be ignored because all observations were performed within $15 \mathrm{~min}$. 


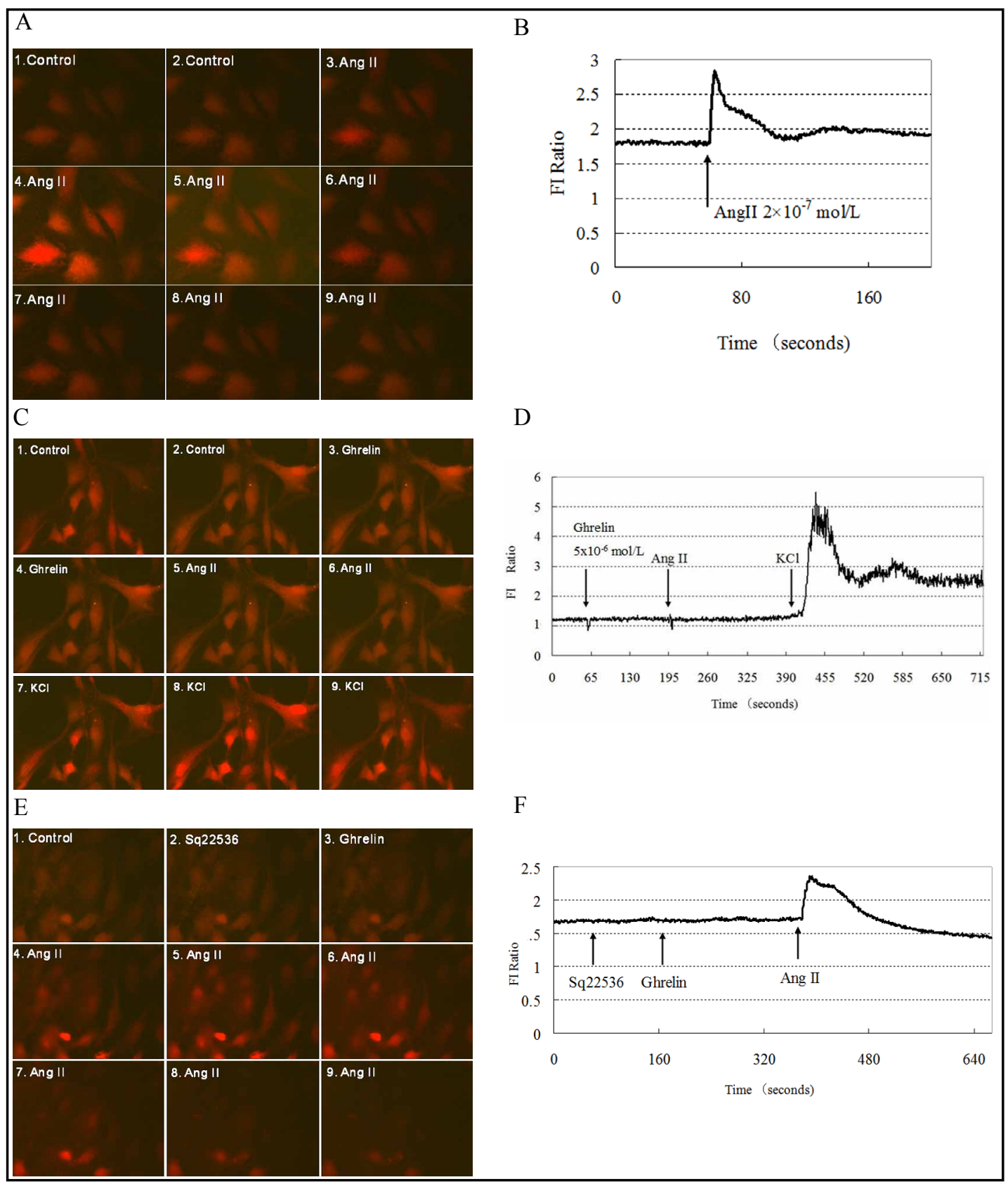

Fig. 4. Effects of ghrelin on the calcium FI in VSMCs during the interactions of ghrelin with AngII, KCl, and Sq22536. (A) Calcium FI after AngII administration. AngII image nos. 4 and 5 are brighter than the control images, indicating that calcium FI was enhanced. In contrast, reduced luminance was observed in the no. 6 AngII image, indicating that calcium FI was attenuated. Such dynamic variation in the luminescence induced by AngII coincided with the FI ratio time curve shown in (B). (C) Calcium FI when VSMCs were preincubated with $5 \times 10^{-6} \mathrm{~mol} / \mathrm{L}$ ghrelin. Image nos. 3 and 4 were not different from the control images, indicating that the administration of ghrelin did not directly affect calcium FI. Moreover, AngII image nos. 5 and 6 did not exhibit the same increasing effects as Fig. 3A, indicating that preincubation with ghrelin inhibited the enhancing effect of AngII. Then, when $4 \times 10^{-2} \mathrm{~mol} / \mathrm{L} \mathrm{KCl}$ was administered, as shown in image nos. 7, 8, and 9 , the brightness of the images increased, indicating that calcium FI was increased by KCl. Such dynamic changes were also observed in the FI ratio time curve (D). (E) Calcium FI when VSMCs were preincubated with $1 \times 10^{-5} \mathrm{~mol} / \mathrm{L} \mathrm{Sq} 22536$ and $5 \times 10^{-6} \mathrm{~mol} / \mathrm{L}$ ghrelin. AngII image nos. 4, 5, and 6 were brighter then the control image, indicating that Sq22536 inhibited the antagonizing effects of ghrelin on AngII. Such dynamic variations were also observed in the FI ratio time curve $(\mathrm{F})$. 
Fig. 5. Effects of ghrelin on the calcium FI ratio in VSMCs during the interactions between ghrelin and (D-Lys ${ }^{3}$ )-GHRP-6. Time curve of the intracellular calcium FI changes induced by the successive administration of $5 \times 10^{-6} \mathrm{~mol} / \mathrm{L}$ ghrelin, $5 \times 10^{-6} \mathrm{~mol} / \mathrm{L}\left(\mathrm{D}-\mathrm{Lys}^{3}\right.$ )-GHRP-6, and AngII. Ghrelin partially inhibited the increase in the calcium FI ratio induced by AngII $(P<0.05)$.

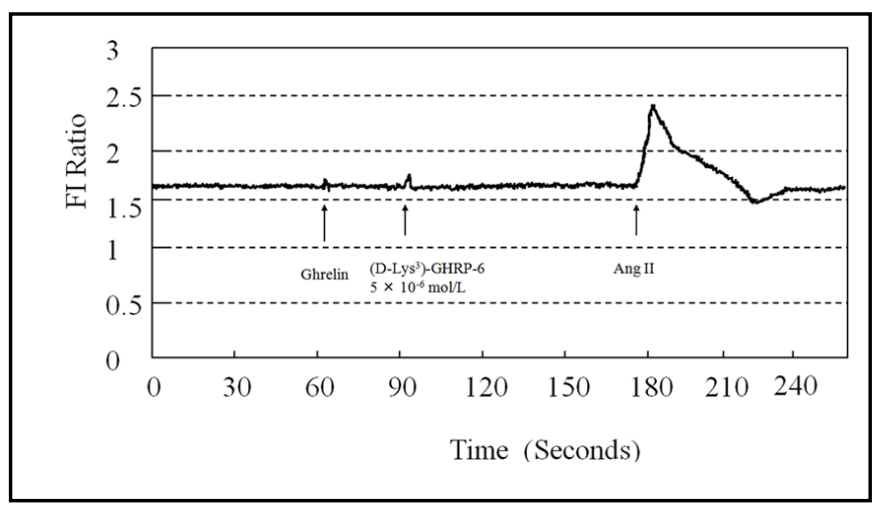

Influence of ghrelin on the calcium FI ratio in resting VSMCs

Figure 3 shows that the administration of $5 \times 10^{-8}$ and $5 \times 10^{-6} \mathrm{~mol} / \mathrm{L}$ ghrelin did not change the intracellular calcium FI ratio in resting VSMCs.

Effects of ghrelin on the calcium FI ratio in VSMCs during interactions of ghrelin with AngII, KCl, and Sq22536

Figure $4 \mathrm{~A}$ and $4 \mathrm{~B}$ show that $2 \times 10^{-7} \mathrm{~mol} / \mathrm{L}$ AngII induced a transient increase in the intracellular calcium FI ratio in VMSCs (FI ratio $155 \pm 40 \%, P<0.05$ compared with the resting state. Preincubation with $5 \times 10^{-6} \mathrm{~mol} / \mathrm{L}$ ghrelin inhibited the vasoconstrictive effect of AngII (FI ratio reduced to $103 \pm 13 \%, P>0.05$ compared with the resting state). However, when $\mathrm{KCl}$ was administered, the intracellular calcium FI ratio was increased in VMSCs (FI ratio $376 \pm 87 \%, P<0.01$ compared with the resting state; Fig. $4 \mathrm{C}$ and $4 \mathrm{D})$. When VMSCs were preincubated with $1 \times 10^{-5} \mathrm{~mol} / \mathrm{L} \mathrm{Sq} 22536$ and $5 \times 10^{-6} \mathrm{~mol} / \mathrm{L}$ ghrelin for 5 and $3 \mathrm{~min}$, respectively, the effects of ghrelin were inhibited, and the vasoconstrictive effect of AngII was revealed (FI ratio enhanced to $163 \pm 23 \%, P<0.05$ compared with the resting state, Fig. $4 \mathrm{E}$ and $4 \mathrm{~F})$.

Effects of ghrelin on the calcium FI ratio in VSMCs during interactions of ghrelin with (D-Lys $\left.{ }^{3}\right)-G H R P-6$ and AngII

Figure 5 reveals that $5 \times 10^{-6} \mathrm{~mol} / \mathrm{L}$ (D-Lys ${ }^{3}$ )-GHRP- 6 can partially block the inhibitory effect of $5 \times 10^{-6} \mathrm{~mol} / \mathrm{L}$ ghrelin on AngII (FI ratio increased to $146 \pm 27 \%, P<0.05$ compared with the resting state), which is consistent with previous findings [22]. The observed specificity of acylated ghrelin was validated by the administration of (D-Lys ${ }^{3}$ )-GHRP-6.

Influence of ghrelin on KCl-induced increase in the calcium FI ratio in VMSCS

Figure $6 \mathrm{~A}$ shows that the calcium FI ratio in resting VSMCs increased to $268 \pm 74 \%$ $\left(P<0.01\right.$ compared with the resting state) by $4 \times 10^{-2} \mathrm{~mol} / \mathrm{L} \mathrm{KCl}$, but this increase could not be sustained. When VSMCs were preincubated with $5 \times 10^{-6} \mathrm{~mol} / \mathrm{L}$ ghrelin for $5 \mathrm{~min}$, the increase in the calcium FI ratio was not inhibited (FI ratio $380 \pm 137 \%, P<0.01$ compared with the resting state). Acceleration of the decrease in the calcium FI ratio was also not obvious following the administration of $5 \times 10^{-6} \mathrm{~mol} / \mathrm{L}$ ghrelin (Fig. 6B).

\section{Discussion}

Effects of ghrelin on the cardiovascular system have been widely reported. Most studies confirmed that ghrelin inhibits proinflammatory cytokine expression as well as apoptosis of endothelial cells and cardiomyocytes in addition to alleviating ischemia/reperfusion injury in rat heart. Furthermore, it contributes to anti-atherosclerosis, protection against myocardial ischemia [31, 36-40], and reduction of blood pressure [17-19, 41-42]. However, other authors reported the contradictory effects of ghrelin on vascular smooth muscles. 

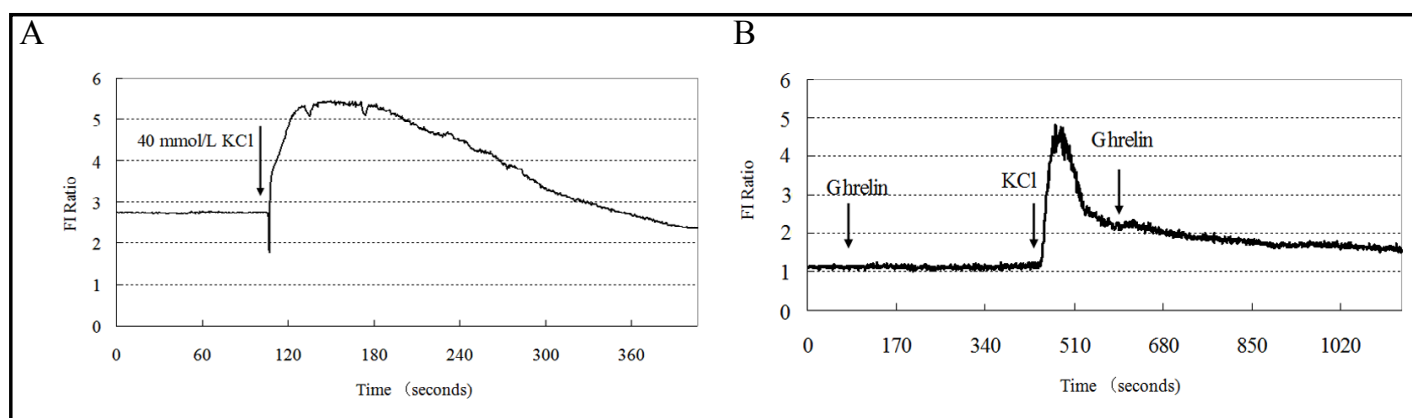

Fig. 6. Effects of ghrelin on the calcium FI ratio in VSMCs during the interactions of ghrelin with KCl. (A) Time curve of the variations of the intracellular calcium FI ratio induced by $\mathrm{KCl}$. Administration of $40 \mathrm{mmol} / \mathrm{L}$ $\mathrm{KCl}$ significantly increased the calcium FI ratio $(P<0.05)$. (B) Time curve of the intracellular calcium FI changes induced by the successive administration of ghrelin and $\mathrm{KCl}$. Ghrelin did not inhibit the increase in the calcium FI ratio induced by $\mathrm{KCl}$.

Initially, some studies concluded that ghrelin was a vasodilator [43], whereas Pemberton reported that ghrelin induces the contraction of rat coronary arteries [21]. Dimitrova found that ghrelin enhances the ET-1-induced contraction of guinea pig renal arteries including endothelium-denuded and intact endothelium vessels, which coincided with the results in guinea pig femoral arteries [20, 23]. Simultaneously, Wiley found that ghrelin significantly decreases the ET-1-induced contraction of human end othelium-denuded mammary arteries [44]. Moazed reported that ghrelin evokes endothelium-dependent vasodilatation of the rat mesenteric vascular bed [45]. Nevertheless, no clinical or bench study has investigated the effects of ghrelin on intracellular calcium concentrations. The roles of ghrelin in vasoactive mechanisms remain unknown.

The present study was the first to investigate the effects of ghrelin on intracellular calcium concentration using VSMCs. The most important finding in this study is that ghrelin inhibits the increase in the calcium concentration induced by AngII (Fig. 4C and 4D), although it does not affect the calcium concentration of resting VSMCs when administered directly (at concentrations of $5 \times 10^{-8} \mathrm{~mol} / \mathrm{L}$ and $5 \times 10^{-6} \mathrm{~mol} / \mathrm{L}$, Fig. 3). This antagonistic effect of ghrelin on AngII could be reversed by the AC inhibitor Sq22536 (Figs. 4E and 4F). We also found that ghrelin had no effects on the increase in the calcium concentration induced by $\mathrm{KCl}$ (Fig. 5A and 5B). The interactions of ghrelin and the other vascular adjusting factors (including AngII and $\mathrm{KCl}$ ) are complicated. It is helpful to clarify the pathophysiological mechanisms of ghrelin together with its pharmacological applications to achieve a deeper understanding of its interactions.

The detailed mechanisms of the interactions between ghrelin and AngII are unclear. AngII, which binds to the AT ${ }_{1}$ receptor on the VSMC membrane, can activate PLC to produce $\mathrm{IP}_{3}$ and stimulate intracellular calcium release from the sarcoplasmic reticulum (SR). Our findings revealed that preincubation with ghrelin can thoroughly inhibit the increase in the VSMC calcium concentration induced by AngII, whereas pretreating VSMCs with Sq22536 before the administration of ghrelin and AngII inhibits the effect of ghrelin. These data indicate that ghrelin inhibits intracellular calcium release by activating the cAMP/PKA signal pathway, which is consistent with the results reported by Rossi [22] and Tolekova [27], who proved that ghrelin inhibits SMC contraction in a concentration-dependent manner by activating the cAMP/PKA signaling pathway. Thus, we hypothesize that binding of ghrelin to GHS-R1a, increases cAMP production by activated AC, which further activates PKA or PKG and enhances calcium intake in SR. In contrast, the large conductance calcium-activated potassium channels and spontaneous transient outward currents activated by cAMP may also play a role in the mechanisms of ghrelin, which hyperpolarizes membranes and accelerates intracellular calcium discharge [46]. Furthermore, the inhibitory effects of ghrelin on AngII may enable us to understand whether ghrelin is vasodilative or vasoconstrictive in nature. 
Because ghrelin inhibits the vasoconstrictive effects of AngII, our data support that ghrelin has vasodilative effects in rat aorta VSMCs.

To validate the specificity of acylated ghrelin-induced inhibition of AngII-stimulated intracellular calcium elevation, we used a known specific GHS-R1a receptor inhibitor, (D-Lys ${ }^{3}$ )-GHRP-6. Our data indicate that $5 \times 10^{-6} \mathrm{~mol} / \mathrm{L}$ (D-Lys ${ }^{3}$ )-GHRP-6 (1:1 with the concentration of ghrelin, Fig. 5) exerted strong inhibitory effects on ghrelin, and AngIIstimulated intracellular calcium elevation was observed. (D-Lys ${ }^{3}$ )-GHRP-6 is a well-known selective GHS-R1a receptor inhibitor that only competes with the binding of acylated ghrelin $[22,35]$, therefore, the specificity of acylated ghrelin is validated. As to the administration sequence, in our preliminary experiment, we added the inhibitor before ghrelin, and found the (D-Lys3)-GHRP-6 administration would potentially make small intracellular calcium fluorescence. Since the aim of this experiment is only to confirm the specificity of acylated ghrelin-induced inhibition of AngII-stimulated intracellular calcium elevation, we changed the sequence of administration (inhibitor after ghrelin) to eliminate the potential noise.

In the present study, we found that ghrelin did not affect the increase in the calcium concentration induced by $\mathrm{KCl}$. It is known that intracellular calcium concentrations can be enhanced by both intracellular calcium release and extracellular calcium influx, the latter of which is induced by opening of the voltage-dependent calcium channels (VDCCs). This finding indicated that ghrelin has no direct effect on VDCCs or extracellular calcium influx, as preincubation with ghrelin did not inhibit the KCl-induced increase in the calcium concentration in VSMCs.

We also found that ghrelin did not affect the calcium concentration in resting VSMCs when administered directly. This result was consistent with previous studies that reported the analogous conclusion that ghrelin did not induce any significant changes in the spontaneous tone of smooth muscles [20,27,33].

The results of the present study implied the ghrelin possess vasodilative effects. However, the detailed physiological effects of ghrelin remain controversial, as some researchers also reported the contractive mechanisms of ghrelin. Dimitrova reported that ghrelin exerted its contractile effects via Src kinase, MEK, cyclooxygenase 1, and T prostanoid receptor agonists in human mesenteric arteries [47]; Sax also validated the coronary vasoconstrictor effect of ghrelin, which is not mediated by GHS-R1a [33]. These results in different experimental conditions indicate that the mechanisms of ghrelin regarding intracellular calcium concentrations are complicated and affected by multiple factors.

In this study, we investigated the effects of the interaction of ghrelin with AngII and $\mathrm{KCl}$ in VSMCs. We did not find any direct effect of these interactions on intracellular calcium concentrations in resting rat aorta VSMCs or on KCl-induced increases in calcium concentrations. To validate these results, two experiments are needed. First, GHS-R1a expression in VSMCs should be examined. Western blotting confirmed good GHS-R1a expression in VSMCs, which was consistent with analogous previous studies [22,34]. Second, a GHS-R1a agonist should be used to examine the function of GHS-R1a. Unfortunately, no GHS-R1a agonist (such as EP1572 and MK-0677) is commercially available, and we were unable to synthesize this compound because of which this profound experiment could not be completed. The limitation of this study was that we only used the GHS-R1a antagonist (D-Lys ${ }^{3}$ )-GHRP-6 to examine the function of GHS-R1a. There is a possibility that a substantial quantity of acylated ghrelin was desacylated in the cell culture medium during the cell culture experiment between the addition of acylated ghrelin and that of AngII. The potential effects of desacyl ghrelin cannot be ruled out. In a previous study, a ghrelin-deacylating enzyme (acyl-protein thioesterase/lysophospholipase) was purified and identified [48]. This study validated the specificity of acylated ghrelin, and thus, we can hypothesize that desacylated ghrelin does not affect the inhibition of AngII. To verify this hypothesis, acylprotein thioesterase 1/lysophospholipase I should be employed to investigate the effects of desacylated ghrelin [48]. This important experiment could not be performed because this enzyme was not available in our laboratory, which was another limitation of this study. These experiments will be conducted in the future if the reagents become available. We also found 
that ghrelin antagonizes the vasomotor effects of AngII, which suggested the ghrelin has a potential vasodilative effect at the cellular level. In this regard, ghrelin can be considered a potential protective factor against cardiovascular disease. This study only begins to uncover the complicated mechanisms of ghrelin. Future studies should be conducted to clarify the detailed mechanisms of the interactions of ghrelin with vasoactive factors at the cellular level.

\section{Acknowledgements}

HF was supported by the Young Core Research Start Fund of Shanghai Medical School of Fudan University (2010). F-FG was supported by the National Natural Science Foundation of China (No. 81173048). TA was supported by grants from the Japan Society for the Promotion of Science (Grant-in-Aid for Young Scientists, Type B, \#20791025 and Grant-in-Aid for "Scientific Research (C) (General), \# 24592157).

The authors would like to thank Enago (www.enago.jp) for the English language review. We also thank the reviewers for their useful comments.

\section{Reference}

1 Howard AD, Feighner SD, Cully DF, Arena JP, Liberator PA, Rosenblum CI, Hamelin M, Hreniuk DL, Palyha OC, Anderson J, Paress PS, Diaz C, Chou M, Liu KK, McKee KK, Pong SS, Chaung LY, Elbrecht A, Dashkevicz M, Heavens R, Rigby M, Sirinathsinghji DJ, Dean DC, Melillo DG, Patchett AA, Nargund R, Griffin PR, DeMartino JA, Gupta SK, Schaeffer JM, Smith RG, Van der Ploeg LH: A receptor in pituitary and hypothalamus that functions in growth hormone release. Science 1996;273:974-977.

- Date Y, Kojima M, Hosoda H, Sawaguchi A, Mondal MS, Suganuma T, Matsukura S, Kangawa K, Nakazato M: Ghrelin, a novel growth hormone-releasing acylated peptide, is synthesized in a distinct endocrine cell type in the gastrointestinal tracts of rats and humans. Endocrinology 2000;141:4255-4261.

- Kojima M, Hosoda H, Date Y, Nakazato M, Matsuo H, Kangawa K: Ghrelin is a growth-hormone-releasing acylated peptide from stomach. Nature 1999;402:656-660.

4 Mizutani M, Atsuchi K, Asakawa A, Matsuda N, Fujimura M, Inui A, Kato I, Fujimiya M: Localization of acyl ghrelin- and des-acyl ghrelin-immunoreactive cells in the rat stomach and their responses to intragastric ph. Am J Physiol Gastrointest Liver Physiol 2009;297:G974-980.

5 Ueberberg B, Unger N, Saeger W, Mann K, Petersenn S: Expression of ghrelin and its receptor in human tissues. Horm Metab Res 2009;41:814-821.

6 Date Y, Nakazato M, Hashiguchi S, Dezaki K, Mondal MS, Hosoda H, Kojima M, Kangawa K, Arima T, Matsuo H, Yada T, Matsukura S: Ghrelin is present in pancreatic alpha-cells of humans and rats and stimulates insulin secretion. Diabetes 2002;51:124-129.

7 Ferrini F, Salio C, Lossi L, Merighi A: Ghrelin in central neurons. Curr Neuropharmacol 2009;7:37-49.

8 Iglesias MJ, Pineiro R, Blanco M, Gallego R, Dieguez C, Gualillo 0, Gonzalez-Juanatey JR, Lago F: Growth hormone releasing peptide (ghrelin) is synthesized and secreted by cardiomyocytes. Cardiovasc Res 2004;62:481-488.

-9 Cao JM, Ong H, Chen C: Effects of ghrelin and synthetic gh secretagogues on the cardiovascular system. Trends Endocrinol Metab 2006;17:13-18.

10 Muccioli G, Broglio F, Valetto MR, Ghe C, Catapano F, Graziani A, Papotti M, Bisi G, Deghenghi R, Ghigo E: Growth hormone-releasing peptides and the cardiovascular system. Ann Endocrinol (Paris) 2000;61:2731.

-11 Rossi F, Bertone C, Petricca S, Santiemma V: Ghrelin inhibits angiotensin ii-induced migration of human aortic endothelial cells. Atherosclerosis 2007;192:291-297.

12 Vlasova MA, Jarvinen K, Herzig KH: Cardiovascular effects of ghrelin antagonist in conscious rats. Regul Pept 2009;156:72-76.

13 Hosoda H, Kojima M, Matsuo H, Kangawa K: Ghrelin and des-acyl ghrelin: Two major forms of rat ghrelin peptide in gastrointestinal tissue. Biochem Biophys Res Commun 2000;279:909-913. 
14 Sato T, Nakamura Y, Shiimura Y, Ohgusu H, Kangawa K, Kojima M: Structure, regulation and function of ghrelin. J Biochem 2012;151:119-128.

15 Raff H: Total and active ghrelin in developing rats during hypoxia. Endocrine 2003;21:159-161.

16 Sibilia V, Pagani F, Mrak E, Dieci E, Tulipano G, Ferrucci F: Pharmacological characterization of the ghrelin receptor mediating its inhibitory action on inflammatory pain in rats. Amino Acids 2012;43:1751-1759.

17 Garcia EA, Korbonits M: Ghrelin and cardiovascular health. Curr Opin Pharmacol 2006;6:142-147.

18 Shinde UA, Desai KM, Yu C, Gopalakrishnan V: Nitric oxide synthase inhibition exaggerates the hypotensive response to ghrelin: Role of calcium-activated potassium channels. J Hypertens 2005;23:779-784.

19 Tsubota Y, Owada-Makabe K, Yukawa K, Maeda M: Hypotensive effect of des-acyl ghrelin at nucleus tractus solitarii of rat. Neuroreport 2005;16:163-166.

20 Dimitrova DZ, Mihov DN, Wang R, Hristov KL, Rizov LI, Bolton TB, Duridanova DB: Contractile effect of ghrelin on isolated guinea-pig renal arteries. Vascul Pharmacol 2007;47:31-40.

21 Pemberton CJ, Tokola H, Bagi Z, Koller A, Pontinen J, Ola A, Vuolteenaho O, Szokodi I, Ruskoaho H: Ghrelin induces vasoconstriction in the rat coronary vasculature without altering cardiac peptide secretion. Am J Physiol Heart Circ Physiol 2004;287:H1522-1529.

22 Rossi F, Castelli A, Bianco MJ, Bertone C, Brama M, Santiemma V: Ghrelin inhibits contraction and proliferation of human aortic smooth muscle cells by camp/pka pathway activation. Atherosclerosis 2009;203:97-104.

-23 Mladenov MI, Hristov KL, Dimitrova DZ, Schubert R, Lubomirov LT, Gjorgoski IK, Duridanova DB, Gagov HS: Ghrelin signalling in guinea-pig femoral artery smooth muscle cells. Acta Physiol (Oxf) 2008;194:195-206.

24 Okumura H, Nagaya N, Enomoto M, Nakagawa E, Oya H, Kangawa K: Vasodilatory effect of ghrelin, an endogenous peptide from the stomach. J Cardiovasc Pharmacol 2002;39:779-783.

-25 Davenport AP, Bonner TI, Foord SM, Harmar AJ, Neubig RR, Pin JP, Spedding M, Kojima M, Kangawa K: International union of pharmacology. Lvi. Ghrelin receptor nomenclature, distribution, and function. Pharmacol Rev 2005;57:541-546.

-26 Rossi F, Castelli A, Bianco MJ, Bertone C, Brama M, Santiemma V: Ghrelin induces proliferation in human aortic endothelial cells via erk1/2 and pi3k/akt activation. Peptides 2008;29:2046-2051.

-27 Tolekova AN, Hadzhibozheva PV, Iliev RN, Georgiev CK, Trifonova KY, Sandeva RV, Kalfin RE, Ilieva GS: Participation of extracellular ca(2+) or ghrelin in peptide-mediated contraction of strips from rat urinary bladder. Regul Pept 2010;162:79-83.

28 Wang Y, Nishi M, Doi A, Shono T, Furukawa Y, Shimada T, Furuta H, Sasaki H, Nanjo K: Ghrelin inhibits insulin secretion through the ampk-ucp2 pathway in beta cells. FEBS Lett 2010;584:1503-1508.

29 Han XF, Zhu YL, Hernandez M, Keating DJ, Chen C: Ghrelin reduces voltage-gated potassium currents in gh3 cells via cyclic gmp pathways. Endocrine 2005;28:217-224.

-30 Liang QH, Jiang Y, Zhu X, Cui RR, Liu GY, Liu Y, Wu SS, Liao XB, Xie H, Zhou HD, Wu XP, Yuan LQ, Liao EY: Ghrelin attenuates the osteoblastic differentiation of vascular smooth muscle cells through the erk pathway. PLoS One 2012;7:e33126.

-31 Ahluwalia A, Li A, Cheng G, Deng X, Tarnawski AS: Reduced ghrelin in endothelial cells plays important mechanistic role in aging-related impairment of angiogenesis. J Physiol Pharmacol 2009;60:29-34.

-32 Batra VK, McNeill JR, Xu Y, Wilson TW, Gopalakrishnan V: Etb receptors on aortic smooth muscle cells of spontaneously hypertensive rats. Am J Physiol 1993;264:C479-484.

-33 Sax B, Nadasy GL, Turi K, Hirschberg K, Furjesz D, Nagy A, Merkely B, Szabo G, Monos E, Kekesi V: Coronary vasoconstrictor effect of ghrelin is not mediated by growth hormone secretagogue receptor 1a type in dogs. Peptides 2011;32:362-367.

-34 Wu RQ Zhou M, Cui XX, Simms HH, Wang P: Upregulation of cardiovascular ghrelin receptor occurs in the hyperdynamic phase of sepsis. American Journal of Physiology-Heart and Circulatory Physiology 2004;287:H1296-H1302.

-35 Erriquez J, Bernascone S, Ciarletta M, Filigheddu N, Graziani A, Distasi C: Calcium signals activated by ghrelin and d-lys(3)-ghrp-6 ghrelin antagonist in developing dorsal root ganglion glial cells. Cell Calcium 2009;46:197-208.

36 Dubinski A, Zdrojewicz Z: [ghrelin and its influence on cardiovascular system]. Wiad Lek 2007;60:352-355.

37 Hedayati N, Annambhotla S, Jiang J, Wang X, Chai H, Lin PH, Yao Q Chen C: Growth hormone-releasing peptide ghrelin inhibits homocysteine-induced endothelial dysfunction in porcine coronary arteries and human endothelial cells. J Vasc Surg 2009;49:199-207. 
-38 Huang CX, Yuan MJ, Huang H, Wu G, Liu Y, Yu SB, Li HT, Wang T: Ghrelin inhibits post-infarct myocardial remodeling and improves cardiac function through anti-inflammation effect. Peptides 2009;30:2286-2291.

39 Yuan MJ, Huang CX, Tang YH, Wang X, Huang H, Chen YJ, Wang T: A novel peptide ghrelin inhibits neural remodeling after myocardial infarction in rats. Eur J Pharmacol 2009;618:52-57.

-40 Zhang GG, Teng X, Liu Y, Cai Y, Zhou YB, Duan XH, Song JQ, Shi Y, Tang CS, Yin XH, Qi YF: Inhibition of endoplasm reticulum stress by ghrelin protects against ischemia/reperfusion injury in rat heart. Peptides 2009;30:1109-1116.

41 Lin Y, Matsumura K, Fukuhara M, Kagiyama S, Fujii K, Iida M: Ghrelin acts at the nucleus of the solitary tract to decrease arterial pressure in rats. Hypertension 2004;43:977-982.

-42 Nagaya N, Kojima M, Uematsu M, Yamagishi M, Hosoda H, Oya H, Hayashi Y, Kangawa K: Hemodynamic and hormonal effects of human ghrelin in healthy volunteers. Am J Physiol Regul Integr Comp Physiol 2001;280:R1483-1487.

-43 Bedendi I, Alloatti G, Marcantoni A, Malan D, Catapano F, Ghe C, Deghenghi R, Ghigo E, Muccioli G: Cardiac effects of ghrelin and its endogenous derivatives des-octanoyl ghrelin and des-gln14-ghrelin. Eur J Pharmacol 2003;476:87-95.

44 Wiley KE, Davenport AP: Comparison of vasodilators in human internal mammary artery: Ghrelin is a potent physiological antagonist of endothelin-1. Br J Pharmacol 2002;136:1146-1152.

-45 Moazed B, Quest D, Gopalakrishnan V: Des-acyl ghrelin fragments evoke endothelium-dependent vasodilatation of rat mesenteric vascular bed via activation of potassium channels. Eur J Pharmacol 2009;604:79-86.

46 Hayoz S, Beny JL, Bychkov R: Intracellular camp: The "Switch" That triggers on "Spontaneous transient outward currents" Generation in freshly isolated myocytes from thoracic aorta. Am J Physiol Cell Physiol 2007;292:C1502-1509.

47 Dimitrova DZ, Dimitrov SD, Iliev I, Mladenov MI, Hristov KL, Mihov DN, Duridanova DB, Gagov HS: Ghrelin signaling in human mesenteric arteries. J Physiol Pharmacol 2010;61:383-390.

48 Satou M, Nishi Y, Yoh J, Hattori Y, Sugimoto H: Identification and characterization of acyl-protein thioesterase 1/lysophospholipase i as a ghrelin deacylation/lysophospholipid hydrolyzing enzyme in fetal bovine serum and conditioned medium. Endocrinology 2010;151:4765-4775. 